Ambiente \& Água - An Interdisciplinary Journal of Applied Science
ISSN 1980-993X - doi:10.4136/1980-993X
www.ambi-agua.net
E-mail: ambi-agua@agro.unitau.br

\title{
Avaliação da qualidade da água para abastecimento no assentamento de reforma agrária Canudos, Estado de Goiás
}

\author{
doi: 10.4136/ambi-agua.1386 \\ Received: 27 Apr. 2014; Accepted: 18 Aug. 2014

\begin{abstract}
Paulo Sérgio Scalize*; Elaine Franciely dos Santos Barros; Lorena Acelina Soares; Karla Emmanuela Ribeiro Hora; Nilson Clementino Ferreira; Luis Rodrigo Fernandes Baumann
\end{abstract} \\ Universidade Federal de Goiás (UFG), Goiânia, GO, Brasil \\ Programa de Pós-graduação em Engenharia do Meio Ambiente (PPGEMA) \\ *Autor correspondente: e-mail: pscalize.ufg@gmail.com, \\ elainefranciely@gmail.com, acelinasoares@gmail.com, karlaemmanuela@gmail.com, \\ nclferreira@gmail.com, fbaumann@mat.ufg.br
}

\section{RESUMO}

O presente trabalho avaliou a qualidade da água usada pela população do Assentamento Canudos, Goiás, tanto na fonte de abastecimento (captação) como no ponto de consumo (torneiras), além de registrar as condições construtivas e a presença de possíveis focos de contaminação. Os locais foram escolhidos de forma aleatória, considerando no mínimo uma amostra em cada sub-bacia existente no assentamento. Ao todo foram analisadas 35 amostras de água coletadas em 35 lotes (10,6\% do total de lotes) e os parâmetros determinados foram E. coli, turbidez, cor aparente, $\mathrm{pH}$, condutividade elétrica (CE), além da identificação e avaliação dos tipos de captações utilizadas, verificando as conformidades com as normas construtivas e de conservação. A análise de representatividade da amostra foi realizada considerando sua quantidade e qualidade, assim como o erro amostral. Os resultados obtidos apontaram que $77,1 \%$ utilizam poços rasos, $20 \%$ mini poços e 2,9\% nascente. Foram detectadas E. coli em $85,7 \%$ das captações, sendo observada a maior presença nos locais que utilizavam poços rasos, aliadas às piores condições estruturais e de saneamento. As análises mostraram que a qualidade da água consumida pelos moradores do assentamento necessita de melhorias significativas.

Palavras-chave: área rural, pequena comunidade, tratamento de água.

\section{Assessing the quality of the water supply in the agrarian reform settlement of Canudos, State of Goiás}

\section{ABSTRACT}

This study evaluated the quality of the water used by the agrarian reform settlement of Canudos, located in Goiás State, considering water supply sources, consumption sites (taps), well construction conditions and the presence of possible contamination sources. Locations were chosen randomly with at least one sample from each sub-basin in the settlement. Thirty-five samples of water were analyzed in 35 land lots (10.6\% of total) considering the parameters of E. coli, turbidity, apparent color, $\mathrm{pH}$, and electrical conductivity (EC). The 
study also identified and assessed the types of water supply used as well as compliance with construction standards and conservation efforts. The representativeness of the samples was analyzed considering their quantity, quality, and the sampling error. The results showed that $77.1 \%$ of the population use shallow wells, $20 \%$ mini wells and $2.9 \%$ springs. E. coli was found in $85.71 \%$ of all water supply sources; with the greatest concentration in shallow wells with bad structural and inadequate sanitation conditions. The analyses showed that the quality of water consumed by the population of the agrarian reform settlement needs considerable improvement.

Keywords: rural area, small communities, water treatment.

\section{INTRODUÇÃO}

A infraestrutura relacionada ao saneamento possui implicações diretas na salubridade de uma residência e visa gerar impactos positivos no ambiente e consequentemente na saúde e desenvolvimento da população (Hora et al., 2012). Essa deve ser eficiente e acessada igualmente por todos, como prevê a Lei $\mathrm{n}^{\circ} 11.445$, que estabelece diretrizes nacionais para $\mathrm{o}$ saneamento básico (Brasil, 2007). No entanto, pesquisas demonstram que grande parte dos investimentos e infraestruturas está localizada nos centros urbanos quando comparado com as áreas rurais. Tal situação pode gerar impactos no ambiente e na saúde da população rural, além de aumentar os gastos públicos no tratamento de doenças. Gazzinelli et al. (1998), em estudo no Estado de Minas Gerais, sugerem uma relação entre a fonte de água, condições sanitárias e a ocorrência de doenças transmitidas pela água.

Teixeira e Heller (2004) destacam, estudando áreas de assentamento subnormal na cidade de Juiz de Fora - MG, que para o controle das helmintoses intestinais são imprescindíveis a boa cobertura e qualidade dos serviços de abastecimento de água, bem como a eliminação da disposição dos esgotos nos terrenos. Razolini e Günther (2008) relatam que a falta ou a precariedade do acesso a água potável representa uma situação de risco que propicia o aumento da incidência de doenças. Citam ainda que, para reverter esse cenário, seria necessária a implementação integrada de políticas públicas, com ações conjuntas envolvendo saneamento, saúde, habitação entre outras.

A água de consumo humano é um dos mais importantes veículos de enfermidades, o que torna primordial sua avaliação. Para que seja considerada potável, a água deve adequar-se a parâmetros de qualidade estabelecidos na Portaria 2914 do Ministério da Saúde, que dispõe sobre os procedimentos de controle e de vigilância da qualidade da água para consumo humano e seu padrão de potabilidade (Brasil, 2011). Barcelos et al. (2006), estudando duas áreas rurais situadas nas sub-bacias dos ribeirões Água Limpa e Santa Cruz, inseridas no município de Lavras-MG, relatam que, de maneira geral, a água utilizada para consumo doméstico, dessedentação de animais e irrigação de culturas oferece risco à saúde da população estudada, sendo que não encontraram relação entre os tipos de mananciais e o nível de contaminação por coliformes termotolerantes.

As ações de controle de qualidade da água no meio rural, segundo Amaral et al. (2003), por parte das autoridades públicas é praticamente inexistente, ficando a cargo de cada proprietário a responsabilidade de utilização e manutenção das fontes de água utilizadas para o seu próprio abastecimento. Essa postura pode ser considerada incorreta, visto que a população no meio rural muitas vezes não conta com informações adequadas acerca das condições de saneamento, quanto à proteção das fontes de água e os riscos causados pelo armazenamento inadequado da água, fato que aumenta consideravelmente a possibilidade de contaminação e má qualidade da água utilizada para o consumo. Ressalta-se ainda que as diferentes formas de captações podem estar vinculadas às condições socioeconômicas, sendo 
que em razão do baixo custo e facilidade de perfuração, a captação de água em aquífero livre é mais utilizada em áreas rurais no Brasil (Silva e Araújo, 2003).

Diante disso, o presente estudo teve como objetivo avaliar a qualidade da água utilizada no Assentamento Canudos, Goiás, na fonte de abastecimento e no ponto de consumo, bem como a avaliação das condições de abastecimento e a presença de possíveis focos de contaminação.

\section{MATERIAL E MÉTODOS}

O Assentamento Canudos localiza-se na bacia hidrográfica do rio dos Bois, abrangendo os municípios de Palmeiras de Goiás, Campestre de Goiás e Guapó, Estado de Goiás. Possui uma área de aproximadamente 13 mil hectares e abriga 329 famílias assentadas com um total de 987 habitantes, considerando 3 habitantes por lote.

As amostragens de água nas fontes de abastecimento (poço raso - escavado com diâmetro de 1,0 m, mini poço - perfurado com diâmetro de $100 \mathrm{~mm}$ ou nascente) e ponto de consumo (pias e tanques), foram realizadas no período sazonal de cheia, entre os meses de abril e maio em 2011, em um total de 35 lotes (10,6\% do total de lotes do assentamento). Os pontos foram escolhidos de forma aleatória distribuída pela área do assentamento, considerando no mínimo um ponto em cada sub-bacia da área de estudo (Figura 1). Desses, 15 pertencem ao município Campestre, 13 à Palmeiras e 7 à Guapó, dos quais 77,1\% utilizam-se de poços rasos como fonte de abastecimento, 20,0\% mini poço e 2,9\% (1/35) nascente (Figura 1).

As amostras de água foram coletadas, acondicionadas e preservadas de acordo com o Guia da Cetesb (2011) e NBRs 9897 (1987a) e 9898 (1987b). Os parâmetros turbidez, cor aparente, $\mathrm{pH}$, condutividade elétrica (CE) e E. coli, foram analisados conforme preconiza APHA et al. (2005). Durante as amostragens foram identificados os tipos de fontes de abastecimento de água e se estavam condizentes com as normas construtivas e de conservação, conforme orientações da Funasa (2006). Registrou-se a profundidade e nível d'água dos poços rasos, obtendo a coluna de água.

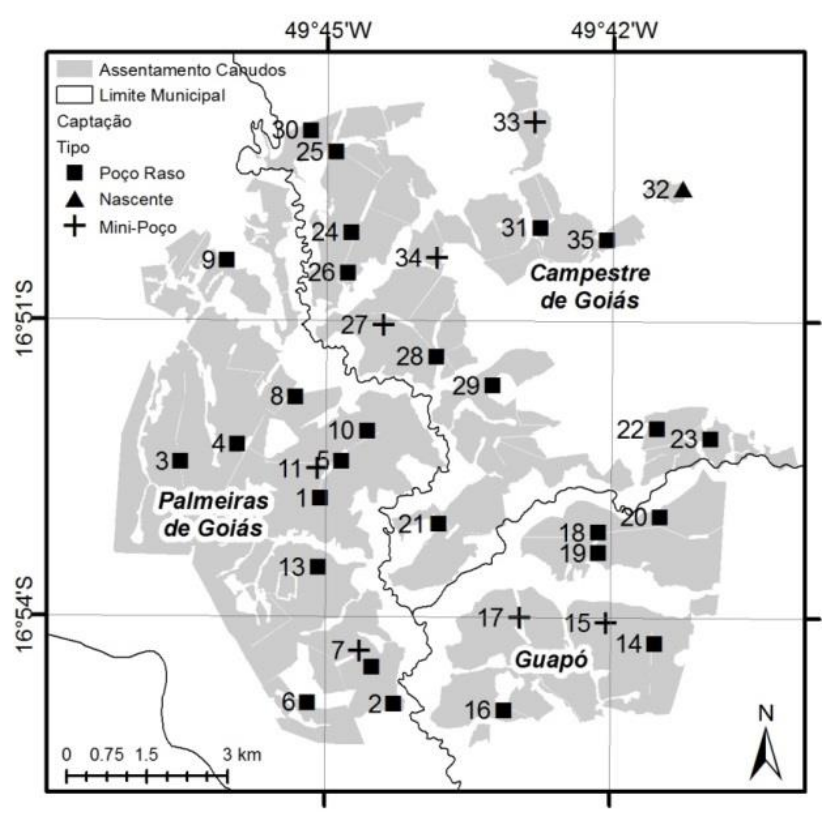

Figura 1. Distribuição espacial dos pontos no Assentamento Canudos-GO, onde foram realizadas coletas de dados e de amostras de água para realização da pesquisa. 
Para avaliar a vulnerabilidade das fontes foi verificada a distância dessas com possíveis focos de contaminações tais como fossas, pocilgas, estábulos e disposição de efluentes e resíduos.

A partir de dados amostrais, distribuídos no espaço, foi realizada estimativa dos valores de cada variável utilizando a geoestatística, que é um ramo da estatística que une o conceito de variáveis aleatórias com o conceito de variáveis regionalizadas (Druck et al., 2004).

A presença de possível erro não amostral foi verificada por meio de um gráfico do tipo boxplot para detectar presença de dados discrepantes (outliers). Os erros amostrais foram avaliados através de intervalos de confiança construídos para estimar médias e proporções populacionais. Um intervalo de confiança para a média ou proporção populacional $\theta$ com nível de confiança $\delta$ foi definido pela Equação 1 e 2.

$$
\begin{aligned}
& I C(\theta, \delta)=\hat{\theta} \pm E \\
& I C(\theta, \delta)=(\hat{\theta}-E, \hat{\theta}+E)
\end{aligned}
$$

em que:

$\widehat{\theta}$ é a estimativa do parâmetro populacional $\theta$;

$E$ é a margem de erro ou também chamado de erro máximo de estimativa, de tal forma que $|\hat{\theta}-\theta|<E$.

O nível de confiança $\delta$ é uma probabilidade, dada pela Equação 3.

$$
P(|\hat{\theta}-\theta|<E)=\delta
$$

ou seja,

se $\hat{\theta}$ é usado como uma estimativa de $\theta$, pode-se então estar $100 \delta \%$ confiantes de que o erro não excederá $E$.

Foram considerados vários níveis de confiança para os intervalos e para cada nível foi observado o erro máximo da estimativa da média e de proporções populacionais. Com isso, obteve-se o grau de precisão dada pela estimativa intervalar baseado nos diferentes níveis de confiança das estimativas. Para o caso da estimativa da média, a margem de erro é definida pela Equação 4.

$$
E=s Z_{\delta} \sqrt{\frac{N-n}{(N-1) n}}
$$

em que:

$s$ é o desvio padrão da amostra,

$\mathrm{Z}_{\delta}$ é o valor crítico que corresponde ao grau de confiança $\delta$,

$N$ é o tamanho da população e $n$ é o tamanho da amostra.

No caso de estimativas proporções, a margem de erro é definida pela equação 5 . 


$$
E=\sqrt{\hat{p}(1-\hat{p})} Z_{\delta} \sqrt{\frac{N-n}{(N-1) n}}
$$

em que:

$\hat{p}$ é uma estimativa da proporção populacional $p$.

\section{RESULTADOS E DISCUSSÃO}

Os resultados das análises das águas coletadas foram apresentados por fonte de abastecimento, bem como as características construtivas e sua localização.

\subsection{Poços rasos}

Na Tabela 1, pode-se observar que $100 \%$ das amostras coletadas nos 27 poços rasos, e em seus respectivos pontos de consumo, apresentaram presença de E. coli. Esses resultados não estão de acordo com o que é preconizado pela Portaria 2914 (Brasil, 2011) que determina a ausência de E. coli em água para consumo humano, visto que sua presença indica contaminação fecal e, consequentemente, a possibilidade de ter-se microrganismos patogênicos, evidenciando a precariedade desse tipo de fonte de abastecimento. Pode-se observar ainda que as amostras com valores inferiores a $100 \mathrm{NMP} / 100 \mathrm{~mL}$ de E. coli representam $63,0 \%$ de ocorrência na fonte e $55,6 \%$ no ponto de consumo. Situação similar foi encontrada por Amaral et al. (2003), estudando uma região rural no Nordeste do Estado de São Paulo, onde evidenciou que 90,0\% das amostras de água das fontes de abastecimento apresentavam condições fora dos padrões microbiológicos para consumo humano. Giatti et al. (2007), analisando 65 amostras coletadas na região da sede do distrito de Iauarerê, área indígena na Amazônia legal, encontraram em 89,2\% das amostras a presença de coliformes termotolerantes, indicando uma água imprópria para consumo humano. Outros estudos mostram condições similares com relação à qualidade da água (Wright et al., 2004; França e Silveira, 2011; Araújo et al., 2011; Schmidt e Dotto, 2012; Almeida et al., 2013).

Pode-se observar na Tabela 1 que os valores de cor aparente apresentaram-se dentro dos padrões de potabilidade $(<15 \mathrm{uH})$ em $55,6 \%$ e $51,9 \%$ das amostras coletadas, na fonte e no ponto de consumo, respectivamente. Já a turbidez, em 40,7\% das amostras na fonte e em $48,1 \%$ das amostras coletadas no ponto de consumo, esteve em conformidade com a Portaria 2914 (Brasil, 2011), sendo que em 7,4\% e 18,5\% foi ultrapassado o limite de 5,0 UNT na captação e no ponto de consumo, respectivamente. A água com baixa turbidez constitui uma medida preventiva, uma vez que sua origem pode ser inorgânica (areia, argila, silte) e/ou orgânica (matéria orgânica, organismos patogênicos). O resultado da análise geoestatística apresentado na Figura 2 permite observar uma tendência do aumento dos valores de E. coli, turbidez e cor aparente na região leste.

Quanto aos valores de $\mathrm{pH}$, três amostras na fonte e duas no ponto de consumo apresentaram-se menores que 6,0, as demais ficaram na faixa recomendada pela legislação, que é de 6,0 a 9,5, apresentando uma média de 6,6 com coeficiente de variação (CV) de 7,7\%.

$\mathrm{Na}$ Tabela 1 e Figura 2 observa-se que a profundidade nos poços rasos variou até $20 \mathrm{~m}$, com uma maior quantidade abaixo de $10 \mathrm{~m}$ (55,5\%). Quanto ao nível de água em relação ao solo, $59,3 \%$ dos poços raros apresentou uma profundidade de até $5,0 \mathrm{~m}$, e o restante entre $5 \mathrm{e}$ $15 \mathrm{~m}$, possibilitando uma altura útil (diferença entre o fundo e o nível de água) entre 1,2 e 6,6 m de coluna d'água. É possível ainda observar que na região oeste do assentamento têm-se maiores profundidades e altura útil de água. Baixa profundidade do poço corrobora com a maior possiblidade de contaminação das águas, pois alturas inferiores a $20 \mathrm{~m}$ diminui o tempo de contato entre a água superficial que infiltra e o solo, que tem a função filtrante (Amaral et al., 2003). Essa altura pode não ser o melhor índice para verificar o risco de 
contaminação da água, pois deve-se também considerar o nível d'água, tipo de solo, padrão construtivo do poço, etc. Na Figura 2 pode-se observar que no lado leste do assentamento têm-se maiores valores de E. coli, turbidez e cor aparente coincidindo com as menores profundidades e alturas úteis de água.

Tabela 1. Quantidade e ocorrências de E. coli, cor aparente e turbidez na fonte de abastecimento (poços rasos e mini poços) e ponto de consumo.

\begin{tabular}{|c|c|c|c|c|c|c|}
\hline \multirow{2}{*}{$\begin{array}{l}\text { Tipo de } \\
\text { Fonte }\end{array}$} & \multirow{2}{*}{ Parâmetro } & \multirow{2}{*}{ Resultado } & \multicolumn{2}{|c|}{ Fonte } & \multicolumn{2}{|c|}{ Ponto de consumo } \\
\hline & & & Quantidade & Ocorrência $(\%)$ & Quantidade & Ocorrência (\%) \\
\hline \multirow{14}{*}{ 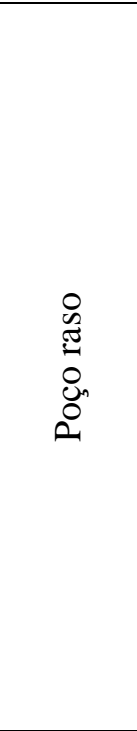 } & \multirow{4}{*}{$\begin{array}{c}\text { E. coli } \\
\text { (NMP/100 mL) }\end{array}$} & Ausentes & 0 & 0,0 & 0 & 0,0 \\
\hline & & 1 a 100 & 17 & 63,0 & 15 & 55,6 \\
\hline & & 101 a 1050 & 9 & 33,3 & 11 & 40,7 \\
\hline & & $>2400$ & 1 & 3,7 & 1 & 3,7 \\
\hline & \multirow{2}{*}{$\begin{array}{c}\text { Cor aparente } \\
\quad(\mathrm{uH})\end{array}$} & $\leq 15$ & 15 & 55,6 & 13 & 51,9 \\
\hline & & $>15$ & 22 & 44,4 & 14 & 48,1 \\
\hline & \multirow{3}{*}{$\begin{array}{l}\text { Turbidez } \\
\text { (UNT) }\end{array}$} & $\leq 1,0$ & 11 & 40,7 & 13 & 48,1 \\
\hline & & 1 a 5 & 14 & 51,9 & 9 & 33,3 \\
\hline & & $>5,0$ & 2 & 7,4 & 5 & 18,5 \\
\hline & \multirow{2}{*}{$\begin{array}{c}\text { Profundidade } \\
(\mathrm{m})\end{array}$} & $<10$ & 15 & 55,5 & $*$ & $*$ \\
\hline & & 10,1 a 20 & 12 & 44,5 & $*$ & $*$ \\
\hline & \multirow{3}{*}{$\begin{array}{l}\text { Nível de água em } \\
\text { relação ao solo } \\
\text { (m) }\end{array}$} & $<5$ & 16 & 59,3 & $*$ & $*$ \\
\hline & & 5 a 10 & 9 & 33,3 & $*$ & $*$ \\
\hline & & 10,1 a 15 & 2 & 7,4 & $*$ & $*$ \\
\hline \multirow{7}{*}{$\begin{array}{l}\stackrel{0}{0} \\
\stackrel{\circ}{2} \\
\vdots \\
\vdots \\
\vdots\end{array}$} & \multirow{2}{*}{$\begin{array}{c}\text { E. coli } \\
\text { (NMP/100 mL) }\end{array}$} & Ausente & 6 & 85,7 & 6 & 85,7 \\
\hline & & $<10$ & 1 & 14,3 & 1 & 14,3 \\
\hline & \multirow{2}{*}{$\begin{array}{c}\text { Cor aparente } \\
(\mathrm{uH})\end{array}$} & $\leq 15$ & 4 & 57,1 & 4 & 57,1 \\
\hline & & $>15$ & 3 & 42,9 & 3 & 42,9 \\
\hline & \multirow{3}{*}{$\begin{array}{l}\text { Turbidez } \\
\text { (UNT) }\end{array}$} & $\leq 1,0$ & 3 & 42,9 & 4 & 57,1 \\
\hline & & 1 a 5 & 2 & 28,6 & 2 & 28,6 \\
\hline & & $>5,0$ & 2 & 28,6 & 1 & 14,3 \\
\hline
\end{tabular}

(*) não aplicável.

Com relação aos possíveis focos de contaminações, foram constatados que em $22,2 \%$ dos lotes não tinham fossa, 18,5\% estavam a uma distância inferior a $15 \mathrm{~m}$ de possíveis focos de contaminação, $33,3 \%$ entre 15 e $30 \mathrm{~m}$ e $26,0 \%$ estavam a uma distância superior a $30 \mathrm{~m}$. Segundo Funasa (2006), deve-se respeitar a distância mínima de $15 \mathrm{~m}$ entre o poço e a fossa seca e a distância de $45 \mathrm{~m}$ para os demais focos de contaminação tais como fossas rudimentares, chiqueiros, estábulos, galinheiros, etc. Em alguns casos foi observada a presença de animais próximos ou sobre os poços, morcegos, baratas, sapos ou girinos no interior dos poços, lançamento de efluentes próximo ao poço e disposição de resíduos de maneira inadequada, o que também colabora para a contaminação das águas.

Foi verificado que os poços possuíam tampas construídas em diferentes materiais, tais como concreto, madeira, materiais alternativos e alguns sem tampa, dos quais 88,9\% sem vedação, possibilitando a entrada de insetos e animais. Segundo Funasa (2006), recomenda-se o uso de tampas a fim de impedir a entrada de objetos que possam trazer prejuízos à qualidade da água. Observou-se que 3 poços $(11,1 \%)$ não tinham prolongamento acima do nível do solo possibilitando a contaminação das águas pela entrada de água de enxurradas ou por meio de despejo superficial, além do que alguns poços também não possuíam revestimento interno. 


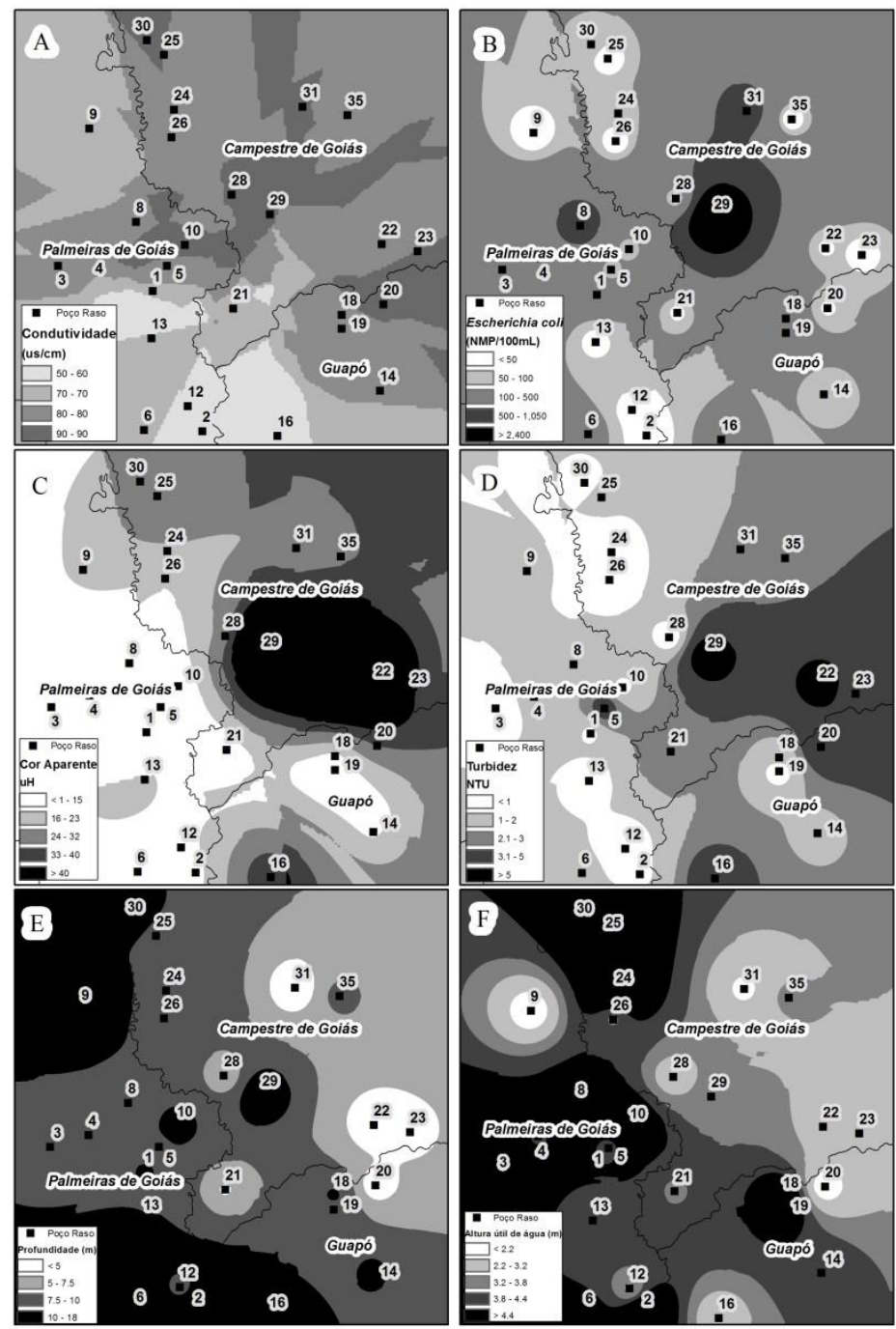

Figura 2. Análise geoestatística dos valores dos parâmetros condutividade elétrica (A), E. coli (B), cor aparente (C) e turbidez (D) obtidos nos ensaios realizados com as amostras coletadas nos poços rasos ao longo da área de estudo. Os valores de profundidade (E) e altura útil de água $(\mathrm{F})$ foram obtidos nas atividades de campo.

\subsection{Mini poços}

Entre os 7 mini poços analisados, 14,3\%, ou seja, apenas um, apresentou presença de E. coli, na água de captação e no ponto de consumo. Na Tabela 1 observa-se que a cor aparente ficou com 42,9\% dos valores acima de $15 \mathrm{uH}$, em ambos locais de amostragem. Quanto à turbidez, com exceção de duas amostras na fonte e uma no ponto de consumo, os valores ficaram abaixo do limite estabelecido na Portaria 2914 (Brasil, 2011).

Apenas uma amostra na fonte apresentou o $\mathrm{pH}$ abaixo de 6,0, as demais ficaram entre $6 \mathrm{e}$ 9,5 (média $=6,7 ; \mathrm{CV}=9,1 \%$ ). Os resultados da $\mathrm{CE}$ foram superiores aos encontrados nas demais fontes, variando de 23 a 330,2 $\mu \mathrm{S} \mathrm{cm}^{-1}$ (média $=116,8 \mu \mathrm{S} \mathrm{cm}^{-1} ; \mathrm{CV}=80,6 \%$ ).

Foi constatada que a profundidade dos mini poços são inferiores a $32 \mathrm{~m}$ e as características construtivas são satisfatórias, dificultando a contaminação da água. Nesses locais, duas situações podem contaminar o lençol freático: através da utilização de equipamentos de bombeamento e canalização sujos ou por meio de infiltrações de contaminantes, isso quando localizado em partes baixas do terreno. Com relação ao foco de contaminação, existe um chiqueiro e uma fossa com $10 \mathrm{~m}$ de distância no ponto $11 \mathrm{e}$, entre os 
demais mini poços, 2 apresentaram fossa com menos de $10 \mathrm{~m}, 3$ entre 22,5 e 27,5 m e 1 com distância de $272 \mathrm{~m}$.

\subsection{Nascente}

Os resultados da única nascente utilizada para abastecimento (ponto 32), mostraram a presença de $E$. coli na fonte (345 NMP/100 mL) e no ponto de consumo (105 NMP/100 mL). Com relação aos demais parâmetros, a cor aparente na captação não atende à Legislação, estando em $40 \mathrm{uH}$. Os valores de turbidez, $\mathrm{pH}$ e CE foram de 1,3 e 0,8 NTU, 111,9 e $115,9 \mu \mathrm{S} \mathrm{cm}^{-1}, 7,2$ e 7,5, respectivamente para a captação e o ponto de consumo. A água captada é transportada por gravidade, estando longe de focos de contaminações.

\subsection{Erro Amostral}

Observa-se na Figura 3 a presença de dados discrepantes, sendo que dentre os parâmetros estudados, a variável pH não apresentou discrepância. Para as outras variáveis, os pontos amostrais que apresentaram discrepância foram analisados para verificar presença de erros não amostrais. Constatou-se que apenas no ponto amostral 29 pode ter ocorrido um erro técnico na coleta dos dados, acarretando a exclusão de tal ponto das análises.

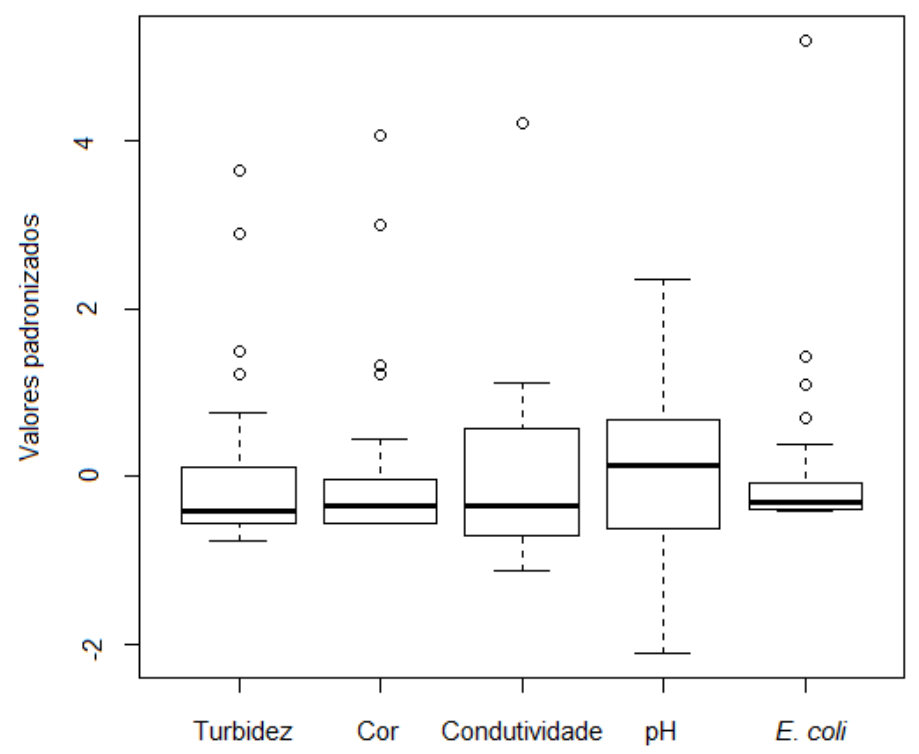

Figura 3. Boxplot dos dados referentes às variáveis relacionadas a fonte de captação de água.

\subsection{Turbidez}

Na Tabela 2 podem ser verificadas as estimativas intervalares da turbidez média e da proporção de lotes com turbidez menor ou igual a 5 UNT, com as respectivas margens de erro das estimativas. Pode-se afirmar, com 99,0\% de confiança, que o intervalo entre $1,1 \mathrm{e}$ 3,6 contém a turbidez média da água no Assentamento Canudos, ou seja, com nível de confiança considerado, pode-se dizer que em média a turbidez está abaixo de 5 UNT.

\subsection{Cor aparente}

Conforme dados constantes na Tabela 2, com 90,0\% de confiança, o intervalo de 15,4 a 47,3 uH contém a cor aparente média da água do Assentamento Canudos, ou seja, em média, esse parâmetro está fora do recomendado pela Portaria 2914 (Brasil, 2011) que limita em 15 uH. Com $95,0 \%$ de confiança, o intervalo de 48,0\% a 63,7\% contém a proporção de lotes com cor aparente na fonte de abastecimento menor que $15 \mathrm{uH}$. 


\subsection{Condutividade Elétrica (CE)}

Esse parâmetro foi analisado considerando uma constante entre Sólidos Totais Dissolvidos (STD) e CE de 0,55. Dessa forma, conforme Tabela 2, pode-se afirmar, com 99,0\% de confiança, que o intervalo de 94,7 a 187,6 mg/L contém a média de STD, ou seja, com esse nível de confiança, podemos considerar que, em média, a água das fontes está abaixo de $1000 \mathrm{mg} / \mathrm{L}$, limite estabelecido na Portaria 2914 (Brasil, 2011). Por outro lado, pode-se afirmar com $99,0 \%$ de confiança que o intervalo de $95,9 \%$ a $98,3 \%$ contém a proporção de lotes com STD em níveis menores ou iguais a $500 \mathrm{mg} / \mathrm{L}$.

\section{8. $\mathbf{p H}$}

Segundo a Portaria 2914 (Brasil, 2011), o valor recomendado para o pH deve estar entre 6,0 e 9,5. Na Tabela 2 encontra-se as estimativas intervalares do $\mathrm{pH}$ médio e da proporção de lotes com $\mathrm{pH}$ na faixa recomendada, com as respectivas margens de erro das estimativas. Pode-se afirmar, com 99,0\% de confiança, que o intervalo entre 6,4 e 6,8 contém o pH médio da água no Assentamento, ou seja, dentro da faixa recomendada.

\subsection{Escherichia coli}

Segundo a Portaria 2914 (Brasil, 2011), as águas de consumo não devem apresentar E. coli. Na Tabela 2 estão as estimativas intervalares para $E$. coli média e da proporção de lotes com ausência de E. coli, com suas respectivas margens de erro. Pode-se afirmar com 99,0\% de confiança, que o intervalo de 30,1 a 187,6 contém a $E$. coli média dos lotes, ou seja, com o nível de confiança 99,0\%, podemos considerar que, em média, as águas não atendem a legislação. Pode-se observar que, com $99,0 \%$ de confiança, o intervalo de $11,6 \%$ a $23,7 \%$ contém a proporção de lotes com ausência de E. coli. Podemos afirmar que a proporção de lotes que atendem as especificações em relação aos níveis de $E$. coli é mínima. Vale ressaltar que a Portaria 2914 recomenda que novas coletas sejam realizadas após a determinação de uma amostra com presença de E. coli.

Tabela 2. Intervalos de confiança e margens de erros para a média $(\mu)$ e a proporção (p) dos parâmetros pesquisados no Assentamento Canudos.

\begin{tabular}{|c|c|c|c|c|c|}
\hline \multirow{2}{*}{ Parâmetro } & \multirow{2}{*}{$\begin{array}{c}\text { Confiança } \\
(100 \delta \%)\end{array}$} & \multicolumn{2}{|c|}{ Média $(\mu)$} & \multicolumn{2}{|c|}{ Proporção (p) } \\
\hline & & $I C(\mu, \delta)$ & Margem de erro & $I C(\mathbf{p}, \delta)$ & $\%$ \\
\hline \multirow{3}{*}{$\begin{array}{l}\text { Turbidez } \\
\text { (UT) }\end{array}$} & $90 \%$ & $(1,53 ; 3,13)$ & 0,80 & $(89,02 \% ; 93,33 \%)$ & 2,15 \\
\hline & $95 \%$ & $(1,38 ; 3,28)$ & 0,95 & $(88,61 \% ; 93,74 \%)$ & 2,56 \\
\hline & $99 \%$ & $(1,08 ; 3,58)$ & 1,25 & $(87,81 \% ; 94,55 \%)$ & 3,37 \\
\hline \multirow{3}{*}{$\begin{array}{l}\text { Cor aparente } \\
(\mathrm{uH})\end{array}$} & $90 \%$ & $(15,43 ; 47,34)$ & 15,95 & $(49,29 \% ; 62,48 \%)$ & 6,59 \\
\hline & $95 \%$ & $(12,37 ; 50,39)$ & 19,01 & $(48,02 \% ; 63,74 \%)$ & 7,85 \\
\hline & $99 \%$ & $(6,40 ; 56,37)$ & 25,98 & $(45,55 \% ; 66,21 \%)$ & 10,32 \\
\hline \multirow{3}{*}{$\begin{array}{l}\text { Condutividade } \\
\text { elétrica }(\mu \mathrm{S} / \mathrm{cm})\end{array}$} & $90 \%$ & $(111,19 ; 159,12)$ & 29,07 & $(96,29 \% ; 97,82 \%)$ & 0,76 \\
\hline & $95 \%$ & $(105,62 ; 168,75)$ & 34,64 & $(96,15 \% ; 97,97 \%)$ & 0,91 \\
\hline & $99 \%$ & $(94,73 ; 187,57)$ & 45,53 & $(95,86 \% ; 98,25 \%)$ & 1,19 \\
\hline \multirow{3}{*}{$\mathrm{pH}$} & $90 \%$ & $(6,47 ; 6,76)$ & 0,14 & $(85,46 \% ; 91,01 \%)$ & 2,77 \\
\hline & $95 \%$ & $(6,44 ; 6,79)$ & 0,17 & $(84,93 \% ; 91,54 \%)$ & 3,31 \\
\hline & $99 \%$ & $(6,39 ; 6,84)$ & 0,23 & $(83,69 \% ; 92,58 \%)$ & 4,34 \\
\hline \multirow{3}{*}{$\begin{array}{l}\text { E. coli } \\
(\mathrm{NMP} / 100 \mathrm{~mL})\end{array}$} & $90 \%$ & $(58,59 ; 159,12)$ & 50,26 & $(13,76 \% ; 21,53 \%)$ & 3,89 \\
\hline & $95 \%$ & $(48,96 ; 168,75)$ & 59,89 & $(13,01 \% ; 22,28 \%)$ & 4,63 \\
\hline & $99 \%$ & $(30,14 ; 187,57)$ & 78,71 & $(11,56 \% ; 23,73 \%)$ & 6,09 \\
\hline
\end{tabular}




\section{CONCLUSÃO}

O presente trabalho permitiu concluir que a água utilizada no Assentamento Canudos não é de boa qualidade na maioria dos pontos de consumo, sendo que a água captada nos mini-poços apresenta qualidade superior àquelas captadas em poços rasos e nascente.

Há predominância do uso de poços rasos, especialmente na porção leste do assentamento, onde se localizam os poços com menores profundidades e alturas úteis, e onde também foram encontradas águas com as piores qualidades.

De acordo com os níveis de confiança e margens de erros considerados, pode-se concluir que existem parâmetros que não atendem às especificações da Portaria 2914/MS, sendo que as variáveis cor aparente e $E$. coli apresentaram os níveis mais críticos em relação aos aceitáveis para consumo humano. Já a turbidez, $\mathrm{pH}$ e condutividade, com certo nível de confiança e margem de erro, se encontram dentro das especificações para consumo humano.

Independente da forma de captação, percebe-se a necessidade de melhoria estrutural, aliada à educação sanitária dos assentados, orientando-os quanto às condições e manutenções a serem feitas nas fontes de captação. Além disso, o incentivo a práticas simples como o uso de filtração, cloração ou fervura da água pode contribuir para uma melhoria na qualidade da água consumida por essa população. Isso poderia ser realizado através de Políticas Públicas.

\section{REFERÊNCIAS}

ASSOCIAÇÃO BRASILEIRA DE NORMAS TÉCNICAS - ABNT. NBR 9897, Planejamento de amostragem de efluentes líquidos e corpos receptores. Rio de Janeiro, 1987a.

ASSOCIAÇÃO BRASILEIRA DE NORMAS TÉCNICAS - ABNT. NBR 9898, Preservação e técnicas de amostragem de efluentes líquidos e corpos receptores. Rio de Janeiro, $1987 b$.

ALMEIDA, J.; FARIA, A.; DALLEMOLE, D. Desenvolvimento socioambiental e passivo hídrico em projetos de assentamento de Mato Grosso. Sociedade e Desenvolvimento Rural, v. 7, n. 4, p. 44-61, 2013.

AMARAL, L. A.; NADER FILHO, A.; ROSSI JUNIOR, O. D.; FERREIRA, L. A.; BARROS, L. S. S. Água de consumo humano como fator de risco à saúde em propriedades rurais. Revista de Saúde Pública, São Paulo, v. 37, n. 4, ago. 2003. http://dx.doi.org/10.1590/S0034-89102003000400017.

AMERICAN PUBLIC HEALTH ASSOCIATION - APHA; AMERICAN WATER WORKS ASSOCIATON - AWWA; WATER ENVIRONMENT FEDERATION - WEF. Standard methods for the examination of water and wastewater. $21 \mathrm{st} \mathrm{Ed}$. Washington, DC, 2005.

ARAÚJO, G. F. R. et al. Qualidade físico-química e microbiológica da água para o consumo humano e a relação com a saúde: estudo em uma comunidade rural no estado de São Paulo. O Mundo da Saúde, v. 35, n. 1, p. 98-104, 2011.

BARCELlOS, M. C.; ROCHA, M.; RODRIGUES, L. S.; COSTA, C. C.; OLIVEIRA, P. R.; SILVA, I. J. et al. Avaliação da qualidade da água e percepção higiênico-sanitária na área rural de Lavras, Minas Gerais, Brasil, 1999-2000. Caderno de Saúde Pública, Rio de Janeiro, v. 22, n. 9, set. 2006. http://dx.doi.org/10.1590/S0102-311X2006000900028. 
BRASIL. Lei $\mathrm{n}^{\mathrm{o}} 11.445$, de 5 de janeiro de 2007. Estabelece diretrizes nacionais para o saneamento básico e dá outras providências. Diário Oficial [da] União, Brasília, 08 jan. 2007.

BRASIL. Ministério de Estado da Saúde. Portaria $n^{\circ}$ 2914, de 12 de dezembro de 2011. Dispõe sobre os procedimentos de controle e de vigilância da qualidade da água para consumo humano e seu padrão de potabilidade. Diário Oficial [da] União, Brasília, 14 dez. 2011.

COMPANHIA AMBIENTAL DO ESTADO DE SÃO PAULO - CETESB. Guia nacional de coleta e preservação de amostras: água, sedimento, comunidades aquáticas e efluentes líquidos. São Paulo, 2011. 326p.

DRUCK, S. CARVALHO, M. S.; CÂMARA, G.; MONTEIRO, A. V. M. Análise espacial de dados geográficos. Brasília: EMBRAPA, 2004.

FRANÇA, E. S.; SILVEIRA, Y. M. S. C. Água, saúde e estratégia saúde da família (ESF): uso e desafios no assentamento Estrelas Do Norte - Motes Claros, Minas Gerais, Brasil. Revista Geográfica de América Central, v. 2, n. 47E, p. 17, 2011.

FUNDAÇÃO NACIONAL DE SAÚDE - FUNASA (Brasil). Manual de saneamento. 3. ed. Brasília, 2006. 408p.

GAZZINELli, A.; SOUZA, M. C. C.; NASCIMENTO, I.; SÁ, I. R.; CADETE, M. M.; KLOOS, H. Domestic water use in a rural village in Minas Gerais, Brazil, with an emphasis on spatial patterns, sharing of water, and factors in water use. Caderno de Saúde Pública, Rio de Janeiro, v. 14, n. 2, abr. 1998. http://dx.doi.org/10.1590/S0102311X1998000200011.

GIATTI, L. L.; ROCHA, A. A.; TOLEDO, R. F.; BARREIRA, L. P.; RIOS, L.; PELICIONI, M. C. F. et al. Condições sanitárias e socioambientais em Iauaretê, área indígena em São Gabriel da Cachoeira, AM. Ciência \& Saúde Coletiva, Rio de Janeiro, v. 12, n. 6, dez. 2007. http://dx.doi.org/10.1590/S1413-81232007000600032.

HORA, K. E. R.; SILVA, M. F.; SOUSA, A. C. L.; OLIVEIRA, V. T.; SCALIZE, P. S. Saneamento rural em áreas de reforma agrária no Brasil. In: ENCONTRO DE ENGENHARIA SANITÁRIA E AMBIENTAL, 15., 2012, Évora. Anais eletrônicos... [S.1.]: APESB, 2012. p. 1-8.

RAZZOLINI, M. T. P.; GUNTHER, W. M. R. Impactos na saúde das deficiências de acesso a água. Saúde e Sociedade, São Paulo, v. 17, n. 1, mar. 2008. http://dx.doi.org/10.1590/S0104-12902008000100003.

SCHMIDT, C. A. P.; DOTTO, K. R. Levantamento microbiológico e de hábitos de consumo de água e alimentos em Santa Helena-PR. Saúde e Pesquisa, v. 5, n. 3, p. 455-461, 2012 .

SILVA, R. C. A.; ARAUJO, T. M. Qualidade da água do manancial subterrâneo em áreas urbanas de Feira de Santana (BA). Ciência \& Saúde Coletiva, São Paulo, v. 8, n. 4, 2003. http://dx.doi.org/10.1590/S1413-81232003000400023.

TEIXEIRA, J. C.; HELLER, L. Fatores ambientais associados às helmintoses intestinais em áreas de assentamento subnormal, Juiz de Fora, MG. Engenharia Sanitária e Ambiental, Rio de Janeiro, v. 9, n. 4, dez. 2004. http://dx.doi.org/10.1590/S141341522004000400006. 
WRIGHT, J.; GUNDRY, S.; CONROY, R. Household drinking water in developing countries: a systematic review of microbiological contamination between source and point-of-use. Tropical Medicine \& International Health, v. 9, n. 1, p. 106-117, 2004. http://dx.doi.org/10.1046/j.1365-3156.2003.01160.x 